\title{
Synthesis and Supramolecular Assembly of Pentacyclic Dithienofluorene and Diselenophenofluorene Derivatives
}

\author{
Chia-Hao Lee, Yu-Ying Lai, Sheng-Wen Cheng, and Yen-Ju Cheng* \\ Department of Applied Chemistry, National Chiao Tung University, 1001 Ta Hsueh Road, Hsin-Chu 30010, Taiwan \\ Supporting Information
}

ABSTRACT: 2,7-Diiodo-3,6-dibromofluorene and 2,7-dichloro-3,6-dibromofluorene have been successfully synthesized. The two key intermediates enable us to implement a regioselective Sonogashira reaction followed by intramolecular thiolate/acetylene cyclization, forming two regiospecific pentacyclic dithieno[2,3-b:7,6- $\left.b^{\prime}\right]$ fluorene (2,7-DTF) and dithieno[3,2-b:6,7-b'] fluorene (3,6-DTF) isomeric molecules, respectively. By using a similar strategy, selenophene-based diselenopheno[2,3-b:7,6-6 $\left.b^{\prime}\right]$ fluorene (2,7-DSF) as well as diselenopheno[3,2-b:6,7- $\left.b^{\prime}\right]$ fluorene (3,6-DSF) were also

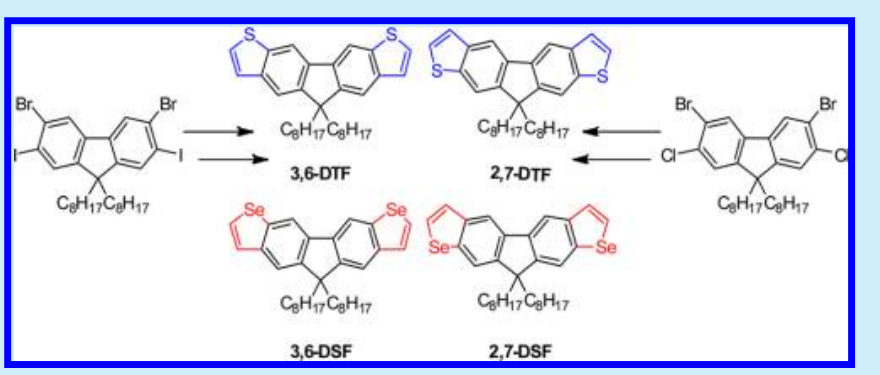
prepared. The isomeric and sulfur/selenium effects determine the optical, electrochemical, and orbital properties. X-ray crystallography revealed that 2,7-DTF and 3,6-DTF molecules assemble into supramolecular helical structures.

$\mathrm{F}$ luorene-based molecules have been the key materials in the field of organic light-emitting diodes due to their high fluorescence quantum yield, hole-transporting property, and excellent chemical stability. ${ }^{1}$ More recently, the fluorene unit emerges as a superb building block to develop p-type semiconductors for solution-processable organic photovoltaics (OPVs) and transistors. ${ }^{2}$ Fluorene derivatives with two aliphatic side chains at the 9-position and the deep-lying HOMO energy level are advantageous for improving the solubility and achieving high obtainable open-circuit voltages. ${ }^{3}$ However, the optical band-gap of the fluorene derivatives is too large to sufficiently harvest solar energy. A molecular modification for improving this structural deficiency is to extend its linear $\pi$-conjugation by fusing aromatic or heteroaromatic rings at the 2,3- and 6,7-junctions of a fluorene. The formation of extended ladder-type structures might enhance intermolecular interactions and facilitate intrinsic charge mobility. ${ }^{4}$

Thiophene or selenophene units are the most suitable components to be integrated with the central fluorene core due to their high hole mobilities, good absorption properties, and selective functionalization at the $\alpha$-positions. By fusing fluorene with two outer thiophene and selenophene units, a new class of pentacyclic dithienofluorene (DTF) and diselenofluorene (DSF) materials will be generated. To the best of our knowledge, these structures have been unreported and thus their applications in organic optoelectronics have never been attempted. It is envisaged that these $\pi$-extended structures would exhibit interesting electronic and optical properties, considering the dithienocarbazole analogies have been described in the literature showing great potential for OPVs. ${ }^{5}$

To create the dithienofluorene (DTF) and diselenofluorene (DSF) structures, the sulfur or selenium atoms in thiophene and selenophene moieties can be placed at either the 2,7- or 3,6-positions of a fluorene, leading to isomeric dithieno[2,3$\left.b: 7,6-b^{\prime}\right]$ fluorene (denoted as 2,7-DTF) and dithieno[3,2-b:6,7$\left.b^{\prime}\right]$ fluorene (3,6-DTF) as well as diselenopheno[2,3-b:7,6$\left.b^{\prime}\right]$ fluorene (2,7-DSF) and diselenopheno[3,2-b:6,7- $\left.b^{\prime}\right]$ fluorene (3,6-DSF) (Scheme 1).

Although the synthesis of 2,7- or 3,6-functionalized fluorene derivatives has been well-documented in the literature, ${ }^{6}$ tandem reactions with regioselective control at the 2,7- and 3,6positions of a fluorene unit have been less explored. In this research, we have synthesized two new building blocks, 2,7diiodo-3,6-dibromofluorene and 2,7-dichloro-3,6-dibromofluorene. These key intermediates enabled us to carry out regioselective Sonogashira reactions followed by thiolate/ selenolate cyclization reactions leading to regiospecific thiophene-based 2,7-DTF and 3,6-DTF as well as selenophene-based 2,7-DSF and 3,6-DSF. The regioisomeric effect and the thiophene/selenophene effect on the electronic and steric properties will be investigated and discussed. Scheme 1 shows the synthetic route of 3,6-DTF and 3,6-DSF. Dialkylation of 3,6-dibromofluorene (1) afforded 3,6-dibromo-9,9-dioctylfluorene (2). Iodination of 2 at the 2,7-positions yielded 3,6-dibromo-2,7-diiodo-9,9-dioctylfluorene (3). Sonogashira coupling reaction of compound 3 selectively took place at iodo over bromo moieties to afford compound $4 . \mathrm{S}_{\mathrm{N}}$ Ar-type reaction of compound 4 and $\mathrm{Na}_{2} \mathrm{~S}$ generated the thiolate intermediate which underwent intramolecular cyclization with the acetylene moieties to form two fused thiophenes in 3,6DTF in a $50 \%$ yield. ${ }^{7}$ In a similar reaction mechanism, reaction of 4 with the selenide reagent prepared from Se power and

Received: December 19, 2013

Published: January 17, 2014 
Scheme 1. Synthesis of Pentacylic 3,6-DTF and 3,6-DSF

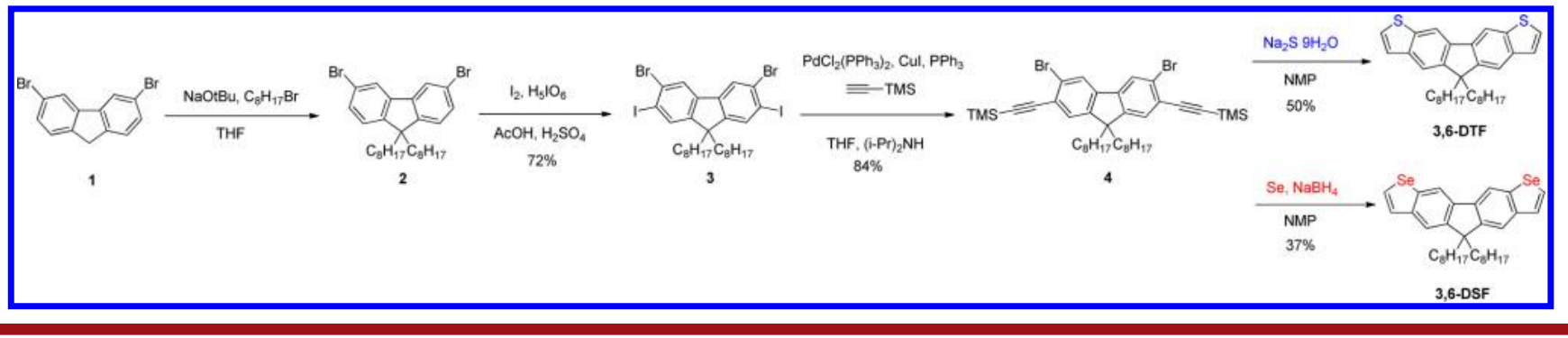

Scheme 2. Synthesis of Pentacylic 2,7-DTF and 2,7-DSF

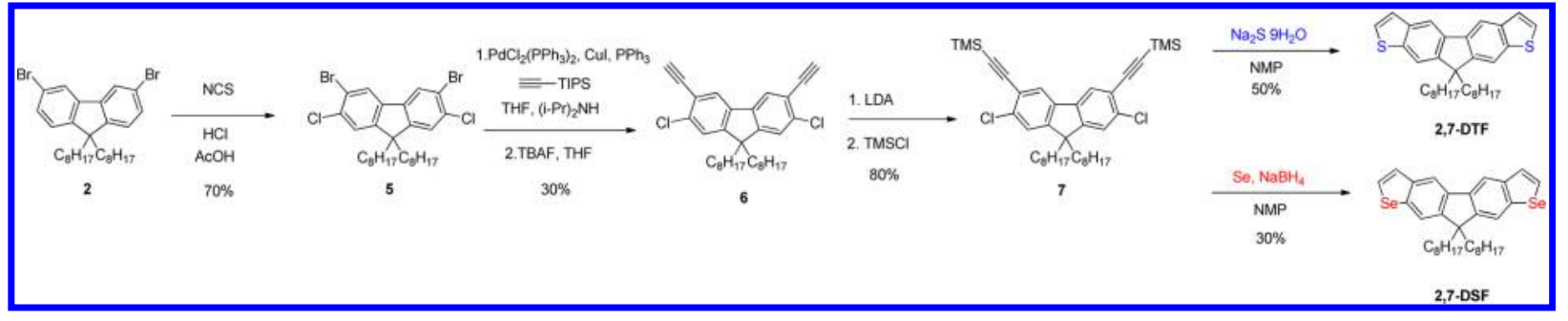

$\mathrm{NaBH}_{4}$ in $\mathrm{N}$-methyl-2-pyrrolidone (NMP) at $190{ }^{\circ} \mathrm{C}$ furnished two fused selenophenes in 3,6-DSF.

The synthesis of other two regioisomers, 2,7-DTF and 2,7DSF is shown in Scheme 2. Chlorination of 3,6-dibromo-9,9dioctylfluorene (2) in the presence of excess amount of $\mathrm{N}$ chlorosuccinimide (NCS) and $\mathrm{HCl} / \mathrm{HOAc}$ afforded 3,6dibromo-2,7-dichloro-9,9-dioctylfluorene (5). Due to the higher reactivity of bromo over chloro functionalities, palladium-catalyzed Sonogashira coupling reaction of compound $\mathbf{5}$ with triisopropylsilyl acetylene (TIPS) selectively occurred at the 3,6-positions. Because the product has the similar polarity with compound $\mathbf{5}$, purification by column chromatography is difficult. Therefore, the TIPS groups were first removed by tetrabutylammonium fluoride (TBAF) to yield compound 6. After purification, the pure compound 6 was reprotected again by the trimethylsilyl (TMS) groups to generate compound 7. Regiospecific cyclization of compound 7 by reacting with $\mathrm{Na}_{2} \mathrm{~S}$ or $\mathrm{Se} / \mathrm{NaBH}_{4}$ in $\mathrm{NMP}$ at $190{ }^{\circ} \mathrm{C}$ successfully achieved the desired 2,7-DTF or 2,7-DSF, respectively. It should be noted that compound 6 without the protection of TMS groups failed to produce the cyclized products.

All of the sulfur and selenium-based isomers exhibit good solubility in common organic solvents. The four compounds were fully characterized by using ${ }^{1} \mathrm{H}$ and ${ }^{13} \mathrm{C} \mathrm{NMR}$, mass spectrometry and X-ray crystallography (see the Supporting Information).

The absorption spectra of 3,6-DTF, 3,6-DSF, 2,7-DTF, and 2,7-DSF with the concentration of $10^{-5} \mathrm{M}$ are shown in Figure 1 for comparison. The absoprtion profiles of all the molecules feature vibronic structures reflecting their rigid and coplanar structures. The absorption profiles also highly depend on the isomeric geometry of the DTF and DTS frameworks. 3,6-DTF exhibited much intense peaks around 300-350 nm compared to 2,7-DTF. The same phenomenon was observed for selenophene-based 3,6-DSF and 2,7-DSF series.

The selenophene-based 2,7-DSF (or 3,6-DSF) showed more red-shifted absorption spectra than the corresponding thiophene-based 2,7-DTF (or 3,6-DTF), ${ }^{8}$ although the absorption profiles are generally similar. Optical band-gaps estimated from absorption edges are 3.58, 3.54, 3.61, and $3.58 \mathrm{eV}$ for 3,6-DTF,

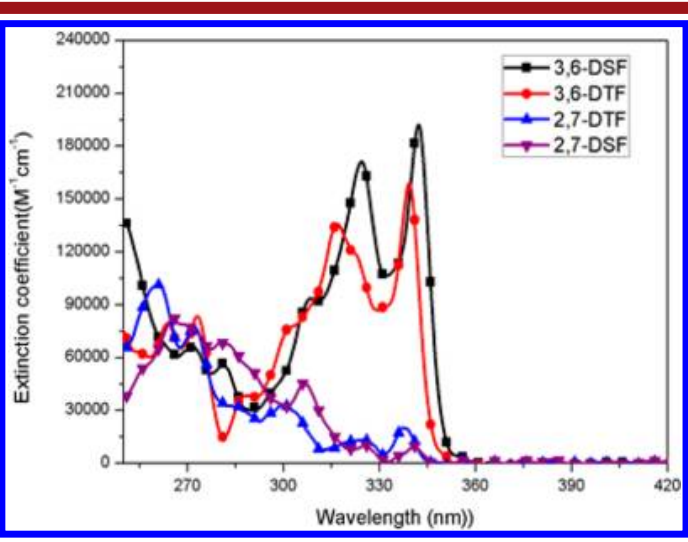

Figure 1. Absorption spectra of all the pentacylic molecules in chloroform with a concentration of $10^{-5} \mathrm{M}$.

3,6-DSF, 2,7-DTF, and 2,7-DSF, respectively, which are much smaller than those of the tricyclic fluorene derivatives. ${ }^{9}$ Cyclic voltammetry of the molecules showed irreversible oxidation curves (Figure S1, Supporting Information) The oxidation peaks were located at $1.10 \mathrm{~V}$ (3,6-DTF), $1.07 \mathrm{~V}$ (3,6-DSF), $1.23 \mathrm{~V}(2,7-\mathrm{DTF})$, and $1.16 \mathrm{~V}$ (2,7-DSF) using $\mathrm{Ag} / \mathrm{AgCl}$ as the reference electrode.

The oxidation potential of the 2,7-series was higher than that of the respective 3,6-series. The HOMO energy levels were determined to be $-5.64,-5.60,-5.75$, and $-5.70 \mathrm{eV}$ for 3,6DTF, 3,6-DSF, 2,7-DTF, and 2,7-DSF, respectively (Table S1, Supporting Information). The LUMO energy levels were roughly deduced by the optical band-gap values and the corresponding HOMO levels $(-2.06 \mathrm{eV}$ for 3,6-DTF, -2.06 $\mathrm{eV}$ for 3,6-DSF, $-2.14 \mathrm{eV}$ for 2,7-DTF, and $-2.12 \mathrm{eV}$ for 2,7DSF).

Quantum-chemical calculations were performed with the Gaussian09 suite using the B3LYP and TD-B3LYP density functionals in combination with the $6-311 G(d, p)$ basis set to understand the molecular orbital properties of the four materials. The octyl substituents are changed to the propyl groups for simplicity. The calculated data are summarized in Table S2 (Supporting Information), and HOMO/LUMO orbitals of the model compounds are shown in Figure 2. The 


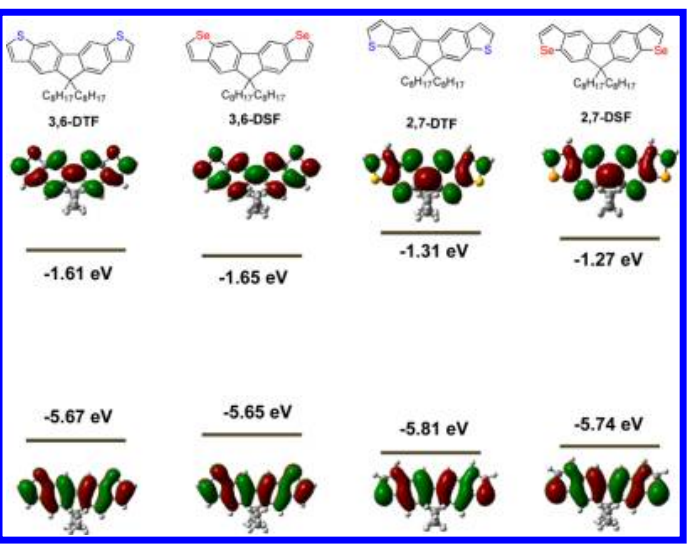

Figure 2. Calculated HOMOs and LUMOs of 3,6-DTF, 3,6-DSF, 2,7DTF, and 2,7-DSF with the B3LYP/6-311G (d, p) level.

relative magnitude of the DFT calculated HOMO energy levels (-5.67 eV for 3,6-DTF, $-5.65 \mathrm{eV}$ for 3,6-DSF, $-5.81 \mathrm{eV}$ for 2,7-DTF, and $-5.74 \mathrm{eV}$ for 2,7-DSF) is qualitatively consistent with the trend of the experimental values. 2,7-DTF showed much lower-lying HOMO energy level which could enhance air-stability and open-circuit voltage. Moreover, 3,6-DTF and 3,6-DSF have smaller HOMO-LUMO band-gaps and much stronger oscillator strengths of the HOMO-LUMO transitions than the 2,7-analogues, suggsting that 3,6-series have more effective conjugation and better HOMO/LUMO symmetry transition. For 3,6-DTF and 3,6-DSF molecules, the double bonds in the thiophene and selenophene subunits are connected to the 2,7-positions of the central fluorene, which would lead to better conjugation due to para-para extension of the central biphenyl skeleton. This calculation result is in good agreement with the fact that 3,6-DTF and 3,6-DSF showed intense absorption signals between 300 and $360 \mathrm{~nm}$.

Single-crystal X-ray crystallographic results were obtained by recrystallization of 2,7-DTF and 3,6-DTF from chloromethane/ethanol cosolvents. These molecules all have nearly planar frameworks, and the aliphatic side chains are almost perpendicular to the molecular backbone.

By viewing the crystal structure of 2,7-DTF along the a-axis (Figure 3a), every two adjacent pentacylic planes are aligned perpendicularly to each other with a short contact distance of ca. $3.0 \AA$. The projection along the $c$-axis looks like a cuboid assembly with the $\mathrm{T}$-shaped pentacyclic planes placed inside and the octyl side chains aligned outside (Figure $3 \mathrm{~b}$ ). From

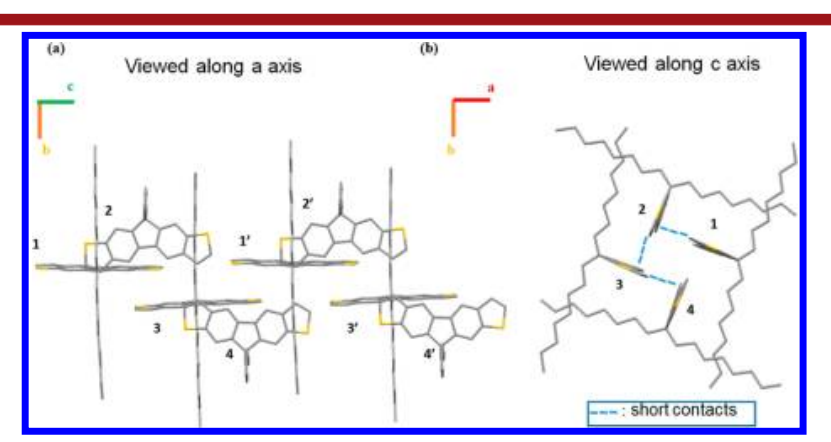

Figure 3. (a) Molecular packing of 2,7-DTF viewed along the $a$-axis. (b) Projection of 2,7-DTF molecular packing viewed along the $c$-axis. The conjugated plane makes a $90^{\circ}$ counterclockwise rotation from 1 to $4,1^{\prime}$ to $4^{\prime}$, and so on. Short contacts are shown as the blue dash lines. Key: yellow, sulfur; gray, carbon. molecule 1 to molecule 4 the conjugated plane consecutively makes a counterclockwise rotation of 90 degree and moves 3.5 A forward to form a supramolcular helicity. Consequently, such a supramolcular structure repeats again every four 2,7-DTF units (from 1 to $4,1^{\prime}$ to $4^{\prime}$, and so on). By looking at the largescale crystal structure along the $c$-axis, the rotational helicity (counterclockwise defined as $\mathrm{M}$ and clockwise defined as $\mathrm{P}$ ) is completely reversed among the adjacent cuboid channels (Figure 4a). 3,6-DTF molecule also shows similar molecular

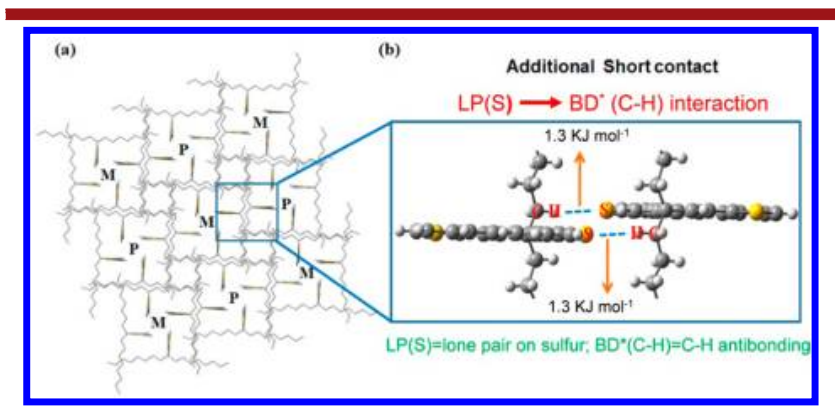

Figure 4. (a) Large-scale 2,7-DTF molecular packing viewed along the $c$-axis. $\mathrm{M}$ and $\mathrm{P}$ represent counterclockwise (left-handed) and clockwise (right-handed) helicities of the supramolecular cuboid channels, respectively. (b) Intermolecular interactions estimated by $\mathrm{NBO}$ analysis on the B3LYP/6-311G(d,p) level of theory for the additional contact in 2,7-DTF. Part of the aliphatic chains is truncated for clarity. Yellow: sulfur; gray: carbon; light-gray: hydrogen.

packing (Figure S3, Supporting Information). Such a molecular self-assembly is extraordinary, considering that they are not assisted through common noncovalent interactions such as hydrogen bonding or $\pi-\pi$ stacking. Notably, there is another short contact between the sulfur atoms in one 2,7-DSF and the protons on the first carbon of the octyl groups in the other 2,7DSF molecule (Figure 4b). Natural bond orbital analysis (NBO) on the B3LYP/6-311G(d,P) level of theory was then used to look into this contact. ${ }^{10}$ It reveals that this contact is a result of orbital interactions between the lone pair of sulfur and the antibonding orbital of the $\mathrm{C}-\mathrm{H}$ bond (Figure $4 \mathrm{~b}$ ). This orbital interaction is estimated computationally to be $1.3 \mathrm{~kJ} /$ mol. However, such additional intermolecular interactions are absent in 3,6-DTF molecules because the sulfur atoms face toward the center of the cuboid channel.

In conclusion, for the first time, 2,7-diiodo-3,6-dibromofluorene and 2,7-dichloro-3,6-dibromofluorene were successfully synthesized. Regioselective Sonogashira reactions of the two key intermediates followed by thiolate/acetylene cyclizations successfully resulted in the formation of regiospecific pentacyclic dithieno[2,3-b:7,6- $\left.\boldsymbol{b}^{\prime}\right]$ fluorene (2,7-DTF) and dithieno[3,2-b:6,7-b'] fluorene (3,6-DTF) molecules, respectively.

Diselenopheno[2,3-b:7,6- $\left.b^{\prime}\right]$ fluorene (2,7-DSF) as well as diselenopheno[3,2-b:6,7- $\left.b^{\prime}\right]$ fluorene $(3,6-D S F)$ were also prepared similarly. The sulfur/selenium and isomeric effects play important roles in determining the optical, electrochemical, and orbital properties. 3,6-Series materials exhibited intense peaks around $300-350 \mathrm{~nm}$ compared to the corresponding 2,7-series, and the selenophene-based series showed more red-shifted absorption than the thiophene-based series. X-ray crystallography revealed that 2,7-DTF and 3,6-DTF molecules assemble into a unique supramolecular helical structure. The four molecules have been further brominated or stannylated for the construction of new polymers or small molecules that are 
highly promising for organic optoelectronics. These new materials are currently under investigation in our laboratory.

\section{ASSOCIATED CONTENT}

\section{S Supporting Information}

Detailed synthesis, cyclic voltammogram, theoretical calculations, X-ray crystallographic data, DSC measurements, emission spectra, and NMR spectra. This material is available free of charge via the Internet at http://pubs.acs.org.

\section{AUTHOR INFORMATION}

\section{Corresponding Author}

*E-mail: yjcheng@mail.nctu.edu.tw.

Notes

The authors declare no competing financial interest.

\section{ACKNOWLEDGMENTS}

We thank the National Science Council, the Ministry of Education, and the Center for Interdisciplinary Science (CIS) of the National Chiao Tung University, Taiwan, for financial support. We thank the National Center of High-Performance Computing (NCHC) in Taiwan for computer time and facilities. We thank Prof. Sue-Lein Wang at National Tsing Hua Uuiversity (NTHU) for help with the X-ray crystallography. Y.J.C. acknowledges the support from the Golden-Jade fellowship of the Kenda Foundation, Taiwan.

\section{REFERENCES}

(1) (a) Li, Y.; Ding, J.; Day, M.; Tao, Y.; Lu, J.; D’Iorio, M. Chem. Mater. 2004, 16, 2165-2173. (b) Guo, X.; Fang, J.; Watari, T.; Tanaka, K.; Kita, H.; Okamoto, K.-i. Macromolecules 2002, 35, 67076713. (c) Ranger, M.; Rondeau, D.; Leclerc, M. Macromolecules 1997, 30, 7686-7691. (d) Lee, S. H.; Nakamura, T.; Tsutsui, T. Org. Lett. 2001, 3, 2005-2007. (e) Yang, J.; Jiang, C.; Zhang, Y.; Yang, R.; Yang, W.; Hou, Q.; Cao, Y. Macromolecules 2004, 37, 1211-1218. (f) Kraft, A.; Grimsdale, A. C.; Holmes, A. B. Angew. Chem. Int. Ed. 1998, 37, 402-428. (g) Meng, H.; Zheng, J.; Lovinger, A. J.; Wang, B.-C.; Van Patten, P. G.; Bao, Z. Chem. Mater. 2003, 15, 1778-1787. (h) Cho, S. Y.; Grimsdale, A. C.; Jones, D. J.; Watkins, S. E.; Holmes, A. B. I. Am. Chem. Soc. 2007, 129, 11910-11911. (i) Ego, C.; Marsitzky, D.; Becker, S.; Zhang, J.; Grimsdale, A. C.; Müllen, K.; MacKenzie, J. D.; Silva, C.; Friend, R. H. I. Am. Chem. Soc. 2002, 125, 437-443.

(2) (a) Chen, M.-H.; Hou, J.; Hong, Z.; Yang, G.; Sista, S.; Chen, L.M.; Yang, Y. Adv. Mater. 2009, 21, 4238-4242. (b) Zhang, F.; Mammo, W.; Andersson, L. M.; Admassie, S.; Andersson, M. R.; Inganäs, O. Adv. Mater. 2006, 18, 2169-2173. (c) Cheng, Y. J.; Yang, S. H.; Hsu, C. S. Chem Rev 2009, 109, 5868-923. (d) Meng, H.; Bao, Z.; Lovinger, A. J.; Wang, B.-C.; Mujsce, A. M. I. Am. Chem. Soc. 2001, 123, 9214-9215. (e) Noh, Y.-Y.; Azumi, R.; Goto, M.; Jung, B.-J.; Lim, E.; Shim, H.-K.; Yoshida, Y.; Yase, K.; Kim, D.-Y. Chem. Mater. 2005, 17, 3861-3870. (f) Huang, F.; Chen, K.-S.; Yip, H.-L.; Hau, S. K.; Acton, O.; Zhang, Y.; Luo, J.; Jen, A. K.-Y. I. Am. Chem. Soc. 2009, 131, 13886-13887.

(3) (a) Zheng, Q.; Jung, B. J.; Sun, J.; Katz, H. E. I. Am. Chem. Soc. 2010, 132, 5394-5404. (b) Chen, J.; Cao, Y. Acc. Chem. Res. 2009, 42, 1709-1718. (c) Vandewal, K.; Tvingstedt, K.; Gadisa, A.; Inganäs, O.; Manca, J. V. Nat. Mater. 2009, 8, 904-909. (d) Chang, C. Y.; Cheng, Y. J.; Hung, S. H.; Wu, J. S.; Kao, W. S.; Lee, C. H.; Hsu, C. S. Adv. Mater. 2012, 24, 549-53. (e) Wu, J. S.; Cheng, Y. J.; Dubosc, M.; Hsieh, C. H.; Chang, C. Y.; Hsu, C. S. Chem Commun 2010, 46, 3259-61.

(4) (a) Fukazawa, A.; Yamaguchi, S. Chem.-Asian I. 2009, 4, 13861400. (b) Scherf, U. I. Mater. Chem. 1999, 9, 1853-1864. (c) Takimiya, K.; Shinamura, S.; Osaka, I.; Miyazaki, E. Adv. Mater. 2011, 23, 43474370. (d) Chen, Y.-L.; Chang, C.-Y.; Cheng, Y.-J.; Hsu, C.-S. Chem.
Mater. 2012, 24, 3964-3971. (e) Cheng, Y. J.; Cheng, S. W.; Chang, C. Y.; Kao, W. S.; Liao, M. H.; Hsu, C. S. Chem. Commun. 2012, 48, 3203-5. (f) Wu, J.-S.; Cheng, Y.-J.; Lin, T.-Y.; Chang, C.-Y.; Shih, P.I.; Hsu, C.-S. Adv. Funct. Mater. 2012, 22, 1711-1722. (g) Wu, J.-S.; Lin, C.-T.; Wang, C.-L.; Cheng, Y.-J.; Hsu, C.-S. Chem. Mater. 2012, 24, 2391-2399. (h) Chang, H.-H.; Tsai, C.-E.; Lai, Y.-Y.; Chiou, D.-Y.; Hsu, S.-L.; Hsu, C.-S.; Cheng, Y.-J. Macromolecules 2012, 45, 92829291. (i) Roncali, J. Chem. Rev. 1997, 97, 173-206. (j) Loser, S.; Bruns, C. J.; Miyauchi, H.; Ortiz, R. o. P.; Facchetti, A.; Stupp, S. I.; Marks, T. J. J. Am. Chem. Soc. 2011, 133, 8142-8145.

(5) (a) Deng, Y.; Chen, Y.; Liu, J.; Liu, L.; Tian, H.; Xie, Z.; Geng, Y.; Wang, F. ACS Appl. Mater. Interfaces 2013, 5, 5741-5747. (b) Deng, Y.; Chen, Y.; Zhang, X.; Tian, H.; Bao, C.; Yan, D.; Geng, Y.; Wang, E. Macromolecules 2012, 45, 8621-8627. (c) Deng, Y.; Liu, J.; Wang, J.; Liu, L.; Li, W.; Tian, H.; Zhang, X.; Xie, Z.; Geng, Y.; Wang, F. Adv. Mater. 2013, DOI: 10.1002/adma.201303586. (d) Kimoto, A.; Tajima, Y. Org. Lett. 2012, 14, 2282-2285.

(6) (a) Wu, Z.; Xiong, Y.; Zou, J.; Wang, L.; Liu, J.; Chen, Q.; Yang, W.; Peng, J.; Cao, Y. Adv. Mater. 2008, 20, 2359-2364. (b) Beaupre, S.; Boudreault, P. L.; Leclerc, M. Adv. Mater. 2010, 22, E6-E27.

(7) (a) Shinamura, S.; Osaka, I.; Miyazaki, E.; Nakao, A.; Yamagishi, M.; Takeya, J.; Takimiya, K. J. Am. Chem. Soc. 2011, 133, 5024-35. (b) Kashiki, T.; Shinamura, S.; Kohara, M.; Miyazaki, E.; Takimiya, K.; Ikeda, M.; Kuwabara, H. Org. Lett. 2009, 11, 2473-2475. (c) Shaw, J. E. L. Org. Chem. 1991, 56, 3728-3729. (d) Cogolli, P.; Maiolo, F.; Testaferri, L.; Tingolo, M.; Tiecco, M. I. Org. Chem. 1979, 44, $2642-$ 2646. (e) Okamoto, T.; Kudoh, K.; Wakamiya, A.; Yamaguchi, S. Chem.-Eur. I. 2007, 13, 548. (f) Okamoto, T.; Kudoh, K.; Wakamiya, A.; Yamaguchi, S. Org. Lett. 2005, 7, 5301.

(8) (a) Zade, S. S.; Zamoshchik, N.; Bendikov, M. Chem.-Eur. J. 2009, 15, 8613-8624. (b) Patra, A.; Bendikov, M. I. Mater. Chem. 2010, 20, 422-433.

(9) Dufresne, S.; Roche, I. U.; Skalski, T.; Skene, W. G. I. Phvs. Chem. 2010, 114, 13106-13112.

(10) Reed, A. E.; Curtiss, L. A.; Weinhold, F. Chem. Rev. 1988, 88, 899-926. 